\title{
Gestão do conhecimento ou gestão de organizações da era do conhecimento? um ensaio teórico-prático a partir de intervenções na realidade brasileira
}

\author{
Rivadávia Correa Drummond de Alvarenga Neto \\ Professor titular da FEAD - \\ riva@alvarenganeto.com.br \\ Ricardo Rodrigues Barbosa \\ Professor titular do Departamento de Teoria e \\ Gestão da Informação da Universidade Federal de \\ Minas Gerais \\ ricardobarbosa@eci.ufmg.br \\ Heitor José Pereira

\section{Professor da Pontifícia Universidade Católica do \\ Paraná \\ heitorrh@terra.com.br}

O artigo relata as motivações, concepções, práticas gerenciais, ênfases, métricas, indicadores e resultados de programas de gestão do conhecimento (GC) em três empresas que atuam no Brasil. Os resultados sugerem que a expressão "gestão do conhecimento" seja ao mesmo tempo um paradoxo e uma impropriedade terminológica. O trabalho conclui também que os principais desafios impostos às organizações comprometidas com a GC são a gestão de mudanças culturais e comportamentais e a criação de um contexto organizacional favorável à criação, uso e compartilhamento da informação e do conhecimento.

Palavra-chave: Gestão do conhecimento; Gestão da informação; Sociedade do conhecimento

\section{knowledge management or management of organizations in the knowledge era? an essay based on interventions on the Brazilian context}

The article describes the motivations, conceptions, managerial practices, priorities, metrics, indicators and results of knowledge management programs in three companies operating in Brazil. The results suggest that 
the expression "knowledge management" is at the same time a paradox and a terminological impropriety. The paper also concludes that the main challenges faced by companies are the management of cultural and behavioral changes and the creation of an organizational context which is favorable to the creation, use and sharing of information and knowledge.

Key-words: Knowledge management; Information management; Knowledge society

Recebido em 16.10.2006 Aceito em 05.02.2007

\section{Introdução}

A transição da velha rigidez dos átomos para a fluidez dos bits nas organizações vem suscitando inúmeras discussões a respeito da miríade de novas terminologias, abordagens gerenciais e ferramentas criadas na denominada Era da Informação ou Era do Conhecimento. Ao mesmo tempo, observa-se que os vultosos investimentos realizados pelas organizações modernas no desenvolvimento de sistemas de informação são direcionados quase que exclusivamente para a tecnologia em si, enquanto pouca ou quase nenhuma atenção é dirigida à informação, às pessoas e seus conhecimentos e à cultura organizacional.

Uma breve análise do cenário atual permite algumas constatações. Em primeiro lugar, a emergência de um novo paradigma tecno-econômico baseado em informação, conhecimento e inovação, junto com a constatação de que as organizações contemporâneas têm investido, cada vez mais, em bens e ativos típicos da era informacional (hardware, software, telecomunicações e redes) do que em bens e ativos típicos da era industrial (máquinas e equipamentos para engenharia de produção). Além disto, existe a percepção, por parte das cúpulas dirigentes das empresas de que a informação e o conhecimento consolidam-se como os principais fatores de diferenciação para a competitividade organizacional. Como conseqüência, observa-se o surgimento de um sem fim de novas abordagens e/ou ferramentas gerenciais atinentes às questões da informação e do conhecimento nas organizações, sob a égide da área denominada gestão do conhecimento organizacional. Dentre essas abordagens e/ou ferramentas, destacam-se as seguintes: gestão de conteúdo, gestão integrada de recursos informacionais, gestão estratégica da informação, gestão do capital intelectual, aprendizagem organizacional, inteligência competitiva, ontologia e memória organizacionais, dentre outros.

Nesse contexto de complexidade e mudanças, constata-se a existência de indefinições conceituais e de toda uma controvérsia acerca da epistemologia da área que vem sendo denominada de Gestão do 
Conhecimento - GC - ou Knowledge Management. Trata-se de uma deriva semântica pop-management ou de uma verdadeira mudança conceitual? Seria este mais um caso de vinhos velhos em garrafas novas ou significa de fato um repensar das estratégias e práticas de gestão para as organizações da era do conhecimento?

A discussão terminológica acerca da GC alimenta-se da indefinição e de toda a controvérsia sobre os conceitos e linhas divisórias entre dado, informação, conhecimento e sabedoria - já de longe discutidas, sem consenso, no campo da sociologia, filosofia, teoria organizacional, ciência da informação e ciência da computação. Tal discussão epistemológica não é objetivo deste trabalho, embora deva ser reconhecido que seu cunho filosófico seja relevante, instigante e intelectualmente estimulante.

A problemática acima descrita motivou a realização de pesquisa com vistas a responder as seguintes perguntas:

Uma vez que a informação e o conhecimento se consolidam como os principais fatores de diferenciação para a competitividade organizacional dos tempos atuais, como as organizações brasileiras entendem, definem, implementam, praticam e avaliam a GC? Que motivações as levaram a essas iniciativas e o que elas esperavam alcançar?

Assim, o presente trabalho descreve as motivações, concepções, práticas gerenciais, ênfases, métricas, indicadores e resultados de programas de GC em três organizações atuantes no Brasil. Além de um esforço analítico e descritivo, os autores propõem um modelo ou mapa conceitual integrativo.

Uma premissa deste ensaio é que o conhecimento só existe na mente humana e no espaço imaginário entre mentes criativas em sinergia de propósitos. O conhecimento, fora deste contexto, é visto como informação e a GC ganha terreno a partir da compreensão de que sua terminologia é metafórica, uma vez que o conhecimento é inerente aos seres humanos e não se transfere ou se compartilha com facilidade ou espontaneidade.

Diversos autores têm discutido, direta ou indiretamente, questões relacionadas ao conhecimento em ambientes organizacionais. Em Drucker (1993) encontra-se a assertiva de que o conhecimento, em detrimento dos fatores de produção capital e trabalho, é a fonte do único recurso significativo na sociedade pós-capitalista. Davenport e Prusak (1998) acrescentam que a única vantagem sustentável de uma empresa é o que ela coletivamente sabe, a eficiência com que ela usa o que sabe e a prontidão com que ela adquire e usa novos conhecimentos. Nessa mesma linha de argumentação, Stewart (1998) inicia seus trabalhos sobre o capital intelectual afirmando que "a informação e o conhecimento são as armas termonucleares competitivas de nossa era". Em contraposição, Senge (1990) sugere que as empresas são incapazes de funcionar como organizações baseadas no conhecimento e Stewart (2002), ao considerar excessivo o gasto das empresas em programas de GC, afirma que as 
empresas falham em descobrir qual é o conhecimento de que necessitam e em como administrá-lo.

Muitos pesquisadores enunciaram definições para a GC. Marchand e Davenport (2004) reconhecem que há um grande componente de gestão da informação na GC e que grande parte do que se faz passar por GC é, na verdade, gestão da informação. Contudo, ainda segundo esses autores, a verdadeira GC vai, em muitos sentidos, bastante além da gestão da informação, ao endereçar aspectos como a criação e o uso do conhecimento. Wilson (2002) examinou a miríade de conceitos atribuídos à GC, re-afirmando toda a polêmica e controvérsia terminológica.

Apesar de toda a polêmica e controvérsia a respeito do termo gestão do conhecimento, Alvarenga Neto (2002) concluiu, com base em sua pesquisa sobre programas de $\mathrm{GC}$, que essa área tem surpreendido aqueles que apostaram em um modismo e tem se estabelecido como um consistente paradigma gerencial do século que se inicia. A gestão estratégica da informação, considerada como ponto de partida para a implementação de programas de GC, norteia e valida amplamente outras atividades e outros temas vinculados à GC, como a gestão do capital intelectual, a aprendizagem organizacional, a criação e transferência do conhecimento, a gestão da inovação, as comunidades de prática e a inteligência competitiva, dentre outros.

A partir dos recortes delineados, são dois os pressupostos deste trabalho. O primeiro é que grande parte do que se convenciona chamar GC é, na verdade, gestão da informação e a gestão da informação é apenas um dos componentes da GC. Contudo, acredita-se que a GC vá além da pura gestão da informação por incluir e incorporar outros aspectos, temas, abordagens e preocupações, como as questões de criação, uso e compartilhamento de informações e conhecimentos, além da criação de contextos organizacionais favoráveis, dentre outros.

Acredita-se que um modelo ou mapa conceitual integrativo de GC possa ser formulado a partir de três concepções básicas, a saber: (a) uma concepção estratégica da informação e do conhecimento; (b) a introdução de tal estratégia nos níveis tático e operacional através das várias ferramentas e abordagens gerenciais e (c) a criação de um espaço organizacional para o conhecimento, o ba ou contexto capacitante, que constitui o conjunto de condições favoráveis para o uso das melhores informações e dos melhores conhecimentos disponíveis..

\section{O contexto: Era da Informação e Organizações do Conhecimento}

A emergência de um paradigma tecno-econômico - PTE - baseado em inovação, informação e conhecimento, bem como a crescente consolidação de tecnologias como a microeletrônica, a tecnologia de informação e as redes de computadores, trazem à tona questões complexas e multifacetadas para as organizações contemporâneas. Um PTE, de acordo Lastres e Albagli (1999), indica o resultado do processo de 
seleção de uma série de combinações viáveis de inovações (técnicas, organizacionais e institucionais), as quais provocam transformações que permeiam e influenciam o comportamento de toda a economia.

Três características definem um conjunto de inovações que se encontram no cerne de cada paradigma, a saber: (a) amplas possibilidades de aplicação; (b) demanda crescente e (c) queda persistente do seu custo unitário. Em sintonia com essas idéias, Castells (2000) sugere que essa mudança contemporânea de paradigma pode ser vista como a transferência de uma tecnologia baseada principalmente em insumos baratos de energia para uma outra que se baseia predominantemente em insumos baratos de informação, os quais resultam do avanço da tecnologia microeletrônica e de telecomunicações. Ao apontar para a economia informacional, esse autor assevera a importância do conhecimento e da informação ao destacá-los como principais características dos novos sistemas econômicos avançados, transcendendo inclusive a importância econômica de outras eras.

De acordo com Stewart (1998), o marco zero da era informacional ou do pós-industrialismo, pelo menos no contexto da economia americana, é o ano de 1991. A análise do autor tomou como base os dispêndios de capital nos Estados Unidos, no período 1965-1991. Comparou-se o dispêndio das empresas americanas com bens de capital típicos da era industrial com o dispêndio de capital com equipamentos de informação, incluindo-se aí computadores e equipamentos de telecomunicações. Conclui-se que, a partir de 1991, as empresas passam a gastar mais com equipamentos que coletam, processam, analisam e disseminam informações e menos com equipamentos típicos da era industrial, como máquinas e equipamentos de engenharia de produção. Embora esses dados reflitam o contexto da economia americana, a era informacional tem chegado, ainda que com certo atraso e ineqüidades, a diversos países em desenvolvimento (ARUNACHALAM, 1999).

O desafio organizacional contemporâneo traduz-se em aprender a nadar em um oceano de informações, prospectando e coletando informações relevantes para a sobrevivência organizacional e para a compreensão de um ambiente de negócios cada vez mais dinâmico e mutável. Destarte, reafirma-se que a evidência deste novo paradigma sugere também a emergência de organizações cujos principais fatores de competitividade sejam pautados no binômio informação-conhecimento. Afinal, qual o significado de organizações do conhecimento ou organizações da era do conhecimento? Para Garvin (1993), uma empresa baseada em conhecimento é uma organização de aprendizagem que reconhece o conhecimento como recurso estratégico e cria conhecimento que pode ser processado internamente e utilizado externamente, aproveitando o potencial de seu capital intelectual, onde o trabalhador do conhecimento é o componente crítico.

Os trabalhadores da organização do conhecimento são profissionais altamente qualificados e com alto grau de escolaridade e, dentre suas habilidades, destarte reunidas em modelos ou portfolios de competências 
de conhecimento, destacam-se o desenvolvimento e a consolidação de boas habilidades organizacionais, boas habilidades em tecnologia de informação e capacidade analítica de solução de problemas. As habilidades cognitivas e as habilidades comportamentais desses trabalhadores contribuem para a formação e o fortalecimento de competências de conhecimento que, aliadas à criatividade e à inteligência, conferem à organização atributos distintivos únicos e específicos.

A ação organizacional tem suas origens na prospecção do ambiente organizacional - interno e externo - em busca de informações relevantes para a compreensão dos negócios, clientes e demais atores ambientais em suas interações complexas. Tal informação pode reduzir ou aumentar a incerteza e, na hipótese da ocorrência da última, cabe à organização a tarefa de promover rodadas sucessivas de negociação e interpretação até que uma construção coletiva ou entendimento compartilhado seja alcançado. A informação retida pelo processo de construção de sentido vitoriosa na proposição ou melhoria de produtos e serviços e na análise rigorosa, meticulosa e sistemática dos processos organizacionais. Tais processos contribuem para a melhoria das decisões e resultam no comprometimento organizacional com determinados cursos de ação.

Os benefícios da administração dos recursos e processos de informação para as organizações do conhecimento são enumerados por Choo (1998). Segundo esse autor, tais organizações (a) tornam-se capazes de adaptação às mudanças do ambiente no momento adequado e de maneira, (b) empenham-se na aprendizagem constante e (c) mobilizam o conhecimento e a experiência de seus membros para gerar inovações.

De acordo com Sveiby (1998), as organizações do conhecimento possuem algumas características precípuas. A primeira delas é a que se refere à qualificação do corpo de colaboradores, responsáveis pela conversão de informação em conhecimento, utilizando-se de suas próprias competências, com ou sem auxílio de fornecedores de informação ou de conhecimento especializado. Uma segunda característica dessas organizações é o fato de elas possuírem poucos ativos tangíveis, ao passo que seus ativos intangíveis representam mais valor ou o verdadeiro valor. O QUAD. 1 ilustra essas idéias e demonstra que a classificação dos ativos intangíveis obedece a uma estrutura tripartite, constituída pela estrutura externa, estrutura interna e competência individual.

QUADRO 1: Valor total de mercado de uma empresa: patrimônio visível e ativos intangíveis.

\begin{tabular}{|l||c|l|l|}
\hline \multicolumn{1}{|c|}{$\begin{array}{c}\text { Patrimônio } \\
\text { Visível : } \\
\text { (valor contábil) }\end{array}$} & \multicolumn{3}{|c|}{$\begin{array}{c}\text { ATIVOS INTANGÍVEIS } \\
\text { (ágio sobre o preço das ações) }\end{array}$} \\
\cline { 2 - 4 } $\begin{array}{l}\text { Ativos tangíveis } \\
\text { menos a dívida } \\
\text { visível }\end{array}$ & $\begin{array}{l}\text { Estrutura Externa: } \\
\text { marcas, relações com } \\
\text { clientes e fornecedores. }\end{array}$ & $\begin{array}{l}\text { Estrutura Interna: } \\
\text { a organização: gerência, } \\
\text { estrutura legal, sistemas } \\
\text { manuais, atitudes, P\&D, } \\
\text { software. }\end{array}$ & $\begin{array}{l}\text { Competência Individual: } \\
\text { escolaridade, experiência. }\end{array}$ \\
\hline
\end{tabular}


Fonte: SVEIBY, 1998, p.14.

As organizações do conhecimento não são ilhas, e sim redes de nós e conexões aparentemente sem limites que constituem redes de significações, conhecimentos e negócios. Neste contexto organizacional, o conteúdo do trabalho também experimenta mudanças significativas, uma vez que informação e conhecimento são tanto a matéria prima quanto o resultado do trabalho.

Os produtos da organização do conhecimento são intensivos em conhecimento e, via de regra, experimentam custos de desenvolvimento muito altos, custos de produção relativamente baixos e custos marginais decrescentes. Por exemplo, as mais recentes drogas da indústria farmacêutica possuem pouca matéria prima e muito conhecimento embutido, resultado de processos de P\&D intensivos e de conhecimentos multidisciplinares combinados. Em contraste, a máquina a vapor, uma inovação radical à sua época, demandava muita matéria prima, consumia horas de trabalho em sua construção e continha relativamente pouco conhecimento quando comparado ao conteúdo de conhecimento embutido nos produtos da contemporaneidade.

Pereira (2002) propõe bases conceituais de um modelo de gestão para organizações baseadas no conhecimento e seu ponto de partida é uma proposta de arquitetura organizacional estruturada em quatro pilares, a saber: (a) estratégia, que foca o conhecimento como a competência essencial da organização; (b) estrutura, que busca a flexibilidade para a criação e disseminação do conhecimento, (c) tecnologia/processos, que incluem as funções de identificação, captura, seleção e validação, organização e armazenagem, compartilhamento, acesso e distribuição, aplicação e criação do conhecimento e (d) pessoas. Esse autor afirma ainda que tais funções são operacionalizadas através de práticas de gestão do conhecimento, tais como a aprendizagem organizacional, gestão do capital intelectual, inteligência empresarial, dentre outros. Esses e outros temas serão também aprofundados em seções ulteriores do presente trabalho. O QUAD2. abaixo, compara, de maneira sintética, os princípios da organização do conhecimento com os princípios organizacionais do paradigma industrial. 
QUADRO 2: Os princípios da organização do conhecimento

\begin{tabular}{|c|c|c|}
\hline ITEM & Visto pelo paradigma industrial & $\begin{array}{l}\text { Visto pelo paradigma do } \\
\text { conhecimento. }\end{array}$ \\
\hline Pessoas & Geradores de custos ou recursos & Geradores de receita \\
\hline Base de poder dos gerentes & $\begin{array}{l}\text { Nível relativo na hierarquia } \\
\text { organizacional }\end{array}$ & Nível relativo de conhecimento \\
\hline Luta de poder & $\begin{array}{l}\text { Trabalhadores físicos versus } \\
\text { capitalistas }\end{array}$ & $\begin{array}{l}\text { Trabalhadores do conhecimento } \\
\text { versus gerentes }\end{array}$ \\
\hline Principal tarefa da gerência & Supervisão de subordinados & Apoio aos colegas \\
\hline Informação & Instrumento de controle & $\begin{array}{l}\text { Ferramenta para o recurso da } \\
\text { comunicação }\end{array}$ \\
\hline Produção & $\begin{array}{l}\text { Trabalhadores físicos processando } \\
\text { recursos físicos para criar recursos } \\
\text { tangíveis }\end{array}$ & $\begin{array}{l}\text { Trabalhadores do conhecimento } \\
\text { convertendo conhecimento em } \\
\text { estruturas intangíveis }\end{array}$ \\
\hline Fluxo de informações & Via hierarquia organizacional & Via redes colegiadas \\
\hline Forma básica de receita & Tangível (dinheiro) & $\begin{array}{l}\text { Intangível (aprendizado, novas } \\
\text { idéias, novos clientes, P\&D) }\end{array}$ \\
\hline Estrangulamentos na produção & $\begin{array}{l}\text { Capital financeiro e habilidades } \\
\text { humanas }\end{array}$ & Tempo e conhecimento \\
\hline Manifestação da produção & Produtos tangíveis (hardware) & $\begin{array}{l}\text { Estruturas intangíveis (conceitos e } \\
\text { software) }\end{array}$ \\
\hline Fluxo de produção & Regido pela máquina, seqüencial & Regido pelas idéias, caótico \\
\hline Efeito de porte & $\begin{array}{l}\text { Economia de escala no processo de } \\
\text { produção }\end{array}$ & Economia de escopo nas redes \\
\hline Relacionamento com o cliente & Unilateral pelos mercados & Interativo pelas redes pessoais \\
\hline Conhecimento & $\begin{array}{l}\text { Uma ferramenta ou um recurso } \\
\text { entre outros }\end{array}$ & O foco empresarial \\
\hline Finalidade de aprendizado & Aplicação de novas ferramentas & Criação de novos ativos \\
\hline Valores do mercado acionário & Regidos pelos ativos tangíveis & Regidos pelos ativos intangíveis \\
\hline Economia & De redução de lucros & De aumento e redução de lucros \\
\hline
\end{tabular}

Fonte: SVEIBY, 1998, p.32.

Feitas essas considerações, e partindo da premissa que organizações do conhecimento são organizações voltadas para a gestão do conhecimento, explorar-se-á o tema em maior profundidade nas linhas que se seguem.

\section{Gestão do conhecimento: de deriva semântica a proposta de mapeamento conceitual integrativo}

Embora muita atenção acadêmica e profissional tenha sido devotada à GC na última década, o conceito ainda não está plenamente consolidado. De fato, a expressão aparenta ser usada de maneiras diferentes em vários domínios. Além disto, cada domínio clama para si que a compreensão parcial do conceito represente a sua articulação definitiva (DAVENPORT e CRONIN, 2000; ALVARENGA NETO, 2002). A propósito dessa indefinição, Davenport e Cronin (2000) indagam: trata-se de uma deriva semântica ou de mudança conceitual? Esses exploram o conceito de GC no contexto da biblioteconomia e ciência da informação, a engenharia de processos e a teoria organizacional.

O modelo de Davenport e Cronin (2000), aqui denominado tríade da GC, pode ser utilizado para identificar conflitos ou embates territoriais 
e contribuir para um entendimento coletivo entre os atores do espaço da GC nas organizações. No primeiro domínio, o da biblioteconomia e ciência da informação, a GC é predominantemente vista como gestão da informação. No segundo domínio, da engenharia de processos, a GC é vista como a gestão do know-how e freqüentemente igualada à tecnologia da informação. Por último, no domínio da teoria organizacional, a GC implica uma mudança conceitual maior, ou seja, o conhecimento deixa de ser visto como recurso e passa ser considerado uma capacidade organizacional. Sob essa última perspectiva, o que é gerenciado não é um recurso, mas o contexto que tal prontidão é manifestada e tal contexto é visto como um espaço de interação entre os conhecimentos tácitos e explícitos de todos os membros de uma organização.

Uma vez estabelecidos alguns fundamentos essenciais, aspectos introdutórios e eixos temáticos, apresenta-se a proposta de um mapeamento conceitual integrativo de gestão do conhecimento que pode ser expresso através da convergência de três pilares: (a) o modelo proposto por Choo (1998), (b) a idéia do contexto capacitante como sugerida por Von Krogh, Ichijo e Nonaka (2001) e (c) a metáfora do guarda-chuva conceitual da GC.

Para Choo (1998), "organizações do conhecimento" são aquelas que fazem uso estratégico da informação para atuação em três arenas distintas e imbricadas, a saber: (a) sensemaking ou a construção de sentido, (b) criação de conhecimento, por intermédio da aprendizagem organizacional e (c) tomada de decisão, com base no princípio da racionalidade limitada de Herbert Simon. Construção de sentido, no presente contexto, refere-se ao processo pelo qual as organizações resolvem a ambigüidade que freqüentemente envolve as mensagens e sinais oriundos do ambiente organizacional externo (WEICK, 1995)

Sob o aspecto de construção de sentido, Choo (1998) afirma que o objetivo imediato do sensemaking é permitir aos membros da organização a construção de um entendimento compartilhado do que é organização e o que ela faz. Reflexões estratégicas devem ser feitas acerca da missão, da visão, dos valores e da cultura organizacional e deve-se também abrir espaço para que as pessoas construam significado para seus trabalhos e suas vidas. O objetivo de longo prazo do sensemaking é a garantia de que as organizações se adaptem e continuem a prosperar em um ambiente dinâmico através da prospecção do ambiente organizacional em busca de informações relevantes que as permitam compreender mudanças, tendências e cenários acerca de clientes, fornecedores, concorrentes e demais atores ambientais.

As organizações enfrentam desafios como a redução da incerteza e - gerenciamento da ambigüidade. Nesse contexto, a inteligência competitiva e do concorrente, a monitoração ambiental, a prospecção tecnológica, a pesquisa de mercado e atividades correlatas são iniciativas empresariais que têm como um de seus objetivos a construção de sentido a respeito de questões para as quais não existem respostas claras. 
A criação do conhecimento é o processo pelo qual organizações criam ou adquirem, organizam e processam a informação, com o propósito de gerar novo conhecimento através da aprendizagem organizacional. O novo conhecimento gerado, por sua vez, permite que a organização desenvolva novas habilidades e capacidades, crie novos produtos e serviços, aperfeiçoe os antigos e melhore seus processos organizacionais. O QUAD. 3 apresenta uma visão comparativa de modelos de criação de conhecimento, conforme autores selecionados.

QUADRO 3: Processos de criação do conhecimento

\begin{tabular}{|c|c|c|}
\hline $\begin{array}{c}\text { PROCESSOS DE } \\
\text { CONHECIMENTO } \\
\text { (WIKSTRÖM \& NORMANN 1994) } \\
\end{array}$ & $\begin{array}{c}\text { FASES DE CRIAÇÃO DO } \\
\text { CONHECIMENTO } \\
\text { (NONAKA \& TAKEUCHI 1997) } \\
\end{array}$ & $\begin{array}{c}\text { ATIVIDADES CONSTRUTORAS } \\
\text { DE CONHECIMENTO } \\
\text { (LEONARD-BARTON 1998) } \\
\end{array}$ \\
\hline \multirow{2}{*}{$\begin{array}{l}\text { Processos Generativos: } \\
\text { gerando novo conhecimento }\end{array}$} & \multirow{2}{*}{$\begin{array}{l}\text { Compartilhamento do } \\
\text { conhecimento tácito } \\
\text { Criação de conceitos }\end{array}$} & Solução compartilhada de problemas \\
\hline & & Experimentação e prototipagem \\
\hline \multirow{2}{*}{$\begin{array}{l}\text { Processos Produtivos: } \\
\text { operacionalizando novo } \\
\text { conhecimento }\end{array}$} & Justificação de conceitos & \multirow{2}{*}{$\begin{array}{l}\text { Implementação e integração de novas } \\
\text { metodologias e ferramentas }\end{array}$} \\
\hline & Construção de arquétipo & \\
\hline $\begin{array}{l}\text { Processos Representativos: } \\
\text { difundindo e transferindo novo } \\
\text { conhecimento }\end{array}$ & Conhecimento de níveis cruzados & Importação de conhecimento. \\
\hline
\end{tabular}

Fonte: CHOO, 1998, p.130.

O terceiro componente do modelo de Choo (1998) é a que se refere ao processo decisório. Aqui, a empresa deve escolher a melhor opção dentre todas as que se configuram e perseguí-la com base na estratégia empresarial. O processo decisório nas organizações, conforme a visão de March e Simon (1975), é caracterizado pelo princípio da racionalidade limitada. Esse princípio, conforme Choo (1998) e March e Simon (1975) pode resumido com base no fato de que: (a) o processo decisório é dirigido pela busca de alternativas que sejam boas o bastante, em detrimento da busca pela melhor alternativa existente; (b) a escolha de uma alternativa implica a renúncia das demais alternativas e a criação de uma seqüência de novas alternativas ao longo do tempo e (c) uma decisão completamente racional iria requerer informações além da capacidade de coleta da empresa e também um processamento de informações além da capacidade cognitiva dos seres humanos.

A criação do conhecimento organizacional é a ampliação do conhecimento criado pelos indivíduos, se satisfeitas as condições contextuais que devem ser propiciadas pela organização. Isso é o que VON KROGH, ICHIJO \& NONAKA (2001) denominam contexto capacitante. Sob essa ótica, a compreensão da palavra gestão, quando da sua associação com a palavra conhecimento, não deve ser entendida como sinônimo de controle. Este é um passo extraordinariamente complexo, uma vez que crescemos, trabalhamos e aprendemos em uma sociedade industrial, inserida em um modo de produção capitalista que impingiu à 
palavra gestão, no contexto da práxis empresarial, o significado mais nefasto para a palavra controle. Gestão, no contexto capacitante, significa promoção de atividades criadoras de conhecimento em nível organizacional e a GC assume uma nova perspectiva hermenêutica. Assim, gestão do conhecimento passa a significar gestão para o conhecimento. A construção de um contexto capacitante, para Nonaka e Takeuchi (1997) e Von Krogh, Ichijo e Nonaka (2001), depende dos seguintes fatores: intenção ou visão holística do conhecimento organizacional, cultura e comportamento organizacionais, caos criativo, redundância, variedade de requisitos, mobilização dos ativistas do conhecimento, autonomia e delegação de poderes, além de questionamentos acerca da estrutura organizacional, layout e hierarquia, dentre outros.

Finalmente, a metáfora do guarda-chuva conceitual da GC pressupõe que, debaixo do mesmo, são abarcados vários temas, idéias, abordagens e ferramentas gerenciais, concomitantemente distintas e imbricadas. Dentre essas, como já foi dito, podem ser destacados a gestão estratégica da informação, gestão do capital intelectual, aprendizagem organizacional, inteligência competitiva e comunidades de prática, dentre outros. São justamente as inter-relações entre esses vários temas que possibilitam e delimitam a formação de um possível referencial teórico de sustentação, para a GC. Ou seja, defende-se aqui a idéia de que a GC seja vista como uma área guarda-chuva. Assim, o feedback do modelo se dá pela classificação dos temas inseridos no guarda-chuva dentro do modelo de Choo (1998). A inteligência competitiva é uma iniciativa de sensemaking ou construção de sentido, enquanto a gestão estratégica da informação e as comunidades de prática se encaixam na temática de criação de conhecimento.

Uma vez apresentados alguns dos principais modelos associados à gestão do conhecimento, serão apresentados, a seguir, visões e iniciativas concretas das empresas no campo da GC.

\section{A Gestão do Conhecimento em empresas que operam no Brasil}

A estratégia de pesquisa qualitativa, aqui relatada, baseou-se em estudos de casos múltiplos aplicados a estudos organizacionais e gerenciais (YIN, 2001; EISENHARDT, 1989). O estudo foi feito em três empresas que já haviam implantado, à época da pesquisa, programas de gestão do conhecimento. Essas empresas são o Centro de Tecnologia Canavieira - CTC -, a Siemens do Brasil, e a PricewaterhouseCooper PwC -.

A escolha das empresas é importante por mais de um motivo. Em primeiro lugar, a literatura sobre gestão do conhecimento privilegia o relato de experiências internacionais - principalmente de empresas americanas, britânicas e japonesas. Portanto, acredita-se que o presente estudo possa contribuir para um melhor entendimento da nossa realidade 
nacional. Além disto, ao focalizar empresas onde já foram implantados programas de gestão do conhecimento, a pesquisa explora questões concretas a respeito dos objetivos, processos e resultados da GC no contexto empresarial brasileiro. Todos os profissionais entrevistados estão envolvidos direta ou indiretamente com tais programas, seja na qualidade de dirigentes das empresas, como responsáveis pela GC ou como beneficiários de tais programas.

As fontes de dados utilizadas na pesquisa foram, essencialmente, entrevistas semi-estruturadas. Foram realizadas 17 entrevistas com profissionais atuantes nos níveis estratégico, tático e operacional das empresas. Abaixo encontram-se discriminados, por empresa, os cargos dos entrevistados.

Centro de Tecnologia Canavieira:

- Gestor do Conhecimento (líder do programa de gestão do conhecimento)

- Analista de Informações (membro da equipe de gestão do conhecimento)

- Diretor Superintendente (gestor de nível estratégico)

- Coordenador de Transferência de Tecnologia (gestor de nível tático)

- Coordenador de Tecnologia (gestor de nível tático)

- Consultora de Recursos Humanos (profissional de nível operacional).

Siemens do Brasil:

- Gerente de Gestão do Conhecimento e da Informação (líder do programa de gestão do conhecimento)

- Membro da equipe de gestão do conhecimento Gerente de Recursos Humanos (gestor de nível tático)

- Diretor Regional (gestor de nível estratégico)

- Gerente de Vendas (gestor de nível tático)

- Engenheiro de aplicação (profissional de nível operacional).

PricewaterhouseCooper

- Coordenador de GC para América do Sul e Central (líder do programa de gestão do conhecimento)

- Gerente de Documentação e Informação (membro da equipe de gestão do conhecimento)

- Diretora do Departamento de Auditoria e Recursos Humanos (gestor de nível estratégico)

- Gerente Sênior de Consultoria Tributária (gestor de nível tático)

- Gerente de Auditoria (gestor de nível tático)

- Auditor Sênior (profissional de nível operacional).

As 37 questões do roteiro de entrevistas focalizaram aspectos relacionados com a gestão do conhecimento nas empresas, dos quais merecem destaque os motivadores para a implantação da gestão do conhecimento, a natureza do relacionamento da GC com a estratégia empresarial, o processo de criação de conhecimento, a natureza do processo decisório e os principais impactos organizacionais da GC.

A investigação revelou que os principais motivadores para a GC nas organizações estudadas podem ser resumidas nos seguintes aspectos: (a) inexistência de práticas de compartilhamento e proteção de informações e conhecimentos, levando à re-invenção da roda e à duplicação de esforços, 
(b) problemas com a coleta, tratamento, organização e disseminação de informações, denotando ausência de uma gestão estratégica da informação, (c) reconhecimento de que a informação e o conhecimento são os principais fatores de competitividades dos tempos atuais e (d) premência da criação de um contexto capacitante na organização como forma de se lidar com questões culturais e comportamentais. Abaixo encontram-se depoimentos dos entrevistados, nas empresas estudadas, os quais confirmam tais constatações:

"[...]cada área da empresa tinha métodos idiossincráticos de armazenamento, gestão e explicitação de conhecimentos. [...]a empresa está hoje preocupada com o conhecimento porque ele é hoje o principal fator de competitividade. [...] havia problemas na recuperação da informação." (Coordenador de transferência de tecnologia do CTC)

"[...] trinta anos gerando tecnologia e, ao longo do tempo, com o turnover ou aposentadoria, o conhecimento se perdia. [...]a perda de conhecimento gerado era crítico: ineficientes na captura, pessoas levavam seus arquivos próprios com elas..." (Diretor Superintendente do CTC)

"[...]conhecimentos e informações importantes se perdiam e não eram compartilhados." (Gerente de auditoria da PwC)

"[...]o maior ativo da PwC é o conhecimento das pessoas, fazer com que o conhecimento de seus profissionais seja compartilhado." (Diretora do departamento de auditoria e de recursos humanos da PwC)

"[...] acesso rápido aos conhecimentos da organização é um diferencial competitivo." (Gerente de vendas da Siemens)

A pesquisa evidenciou a ausência de consenso acerca de uma definição para a GC nas organizações estudadas. Contudo, alguns termos são comuns nos depoimentos dos entrevistados. Esses termos recorrentes são: processo, informação, conhecimento, inovação, explicitação, registro, compartilhamento, cultura organizacional, acesso e utilização, dentre outros. Eis alguns trechos de depoimentos que confirmam tal assertiva:

"[...] não há consenso sobre o que é ou deva ser GC na organização - é um desafio. [...] GC é um processo, tem fases mas não tem fim. [...] processo que visa facilitar compartilhamento, proteção de ativos intangíveis, dentre os quais o conhecimento." (Gestor do conhecimento do CTC)

[...] não é muito claro, mas é tudo aquilo que se gerencia para a obtenção do conhecimento, inovação." (Diretor superintendente do CTC)

"[...] processo que contribui para colocar os conhecimentos dos colabores em rede." (Diretor Regional da Siemens) 
"[...] não é milagre, não é um 'knowledge unlocker plus'. É muito mais uma mudança da filosofia da gestão estratégica da organização. [...] ferramentas para colaboração e criar canais..." (Gerente de gestão do conhecimento e da informação da Siemens)

"[...] GC é processo, não tem fim. [...] processo para captura de todo o conhecimento que permeia a empresa. [...] disponibilizar, usar e compartilhar para o bem da empresa." (Gerente de documentação e informação da PwC)

"[...]GC é como sustentar um ambiente onde há criação, desenvolvimento, troca e disseminação de conhecimentos estratégicos para a organização - é criar o contexto, é um processo que deveria permear todos os processos de negócios da organização." (Coordenador de GC para América do Sul e Central da PwC)

Em seguida, com o objetivo de verificar a proposta intitulada guarda-chuva conceitual de GC, os entrevistados foram solicitados a responder quais eram os aspectos, abordagens gerenciais e ferramentas considerados sob a égide da área, programa ou projeto de GC, em suas respectivas organizações. As respostas foram agrupadas nas seguintes categorias: (a) monitoração ambiental, inteligência competitiva, pesquisa de mercado; (b) gestão estratégica da informação, gestão eletrônica de documentos, mapeamento de processos, (c) gestão do capital intelectual, competências, pessoas e ativos intangíveis; (d) comunidades de prática, reais e virtuais, (e) aprendizagem organizacional, inclusive e-learning; (f) apoio ao processo decisório e (g) criação de contexto favorável ou capacitante:

"[...] sim, informações do exterior, produtos da concorrência, tendências de mercado, clippings [...] há também uma coleta informal feita por colaboradores que 'pinçam' algo no mercado e colocam na intranet - até mesmo boatos!" (Gerente de Vendas da Siemens)

"[...] a GC é área estratégica ligada à diretoria, levando informações que subsidiam o processo decisório, é assessoria à diretoria." (Gestor do conhecimento do CTC)

"[...] implementar uma rigorosa taxonomia para todo 0 conteúdo organizacional." (Pesquisa documental, CTC, 2005)

Os entrevistados foram inquiridos acerca da ênfase ou aspectos prioritários da GC em suas organizações. Observou-se que a fase inicial e ponto de partida para quaisquer iniciativas de GC, que é gestão estratégica da informação, estava em estágios de quase maturidade, com a consciência de que esse deve ser considerado um processo permanente.

As organizações procuravam avançar para aspectos relativos ao compartilhamento, à cultura organizacional e à criação de contextos 
capacitantes. Ressalta-se a existência de várias iniciativas genuinamente brasileiras adotadas por tais organizações neste sentido, que são o Momento Cultural no CTC e o Happy Hour do Saber na Siemens. Tal iniciativa é

"[...] é uma prática informal de palestras, aonde são compartilhados conhecimentos essenciais da organização de forma mais "tácita" e espontânea. Trata-se de uma iniciativa local específica, que se enquadra na política geral. As palestras tem duração de uma hora e são ministradas por colaboradores da empresa. (todos podem ser palestrantes: colaboradores, estagiários e terceiros)" (Pesquisa Documental, Siemens do Brasil, 2005)

Os resultados demonstraram que a avaliação de práticas de GC, suas métricas e indicadores, envolve um misto de elementos qualitativos e quantitativos. As organizações pesquisadas adotaram posturas e práticas gerenciais avançadas, como o Balanced Scorecard, também conhecido como marcador balanceado e o EVA, ou valor econômico agregado. Como a GC adquire um significado de um repensar da gestão para as organizações da era do conhecimento, as organizações deste estudo, além de adotarem procedimentos já existentes, criaram também suas próprias métricas e indicadores. Neste contexto, podem ser destacados a mensuração do número de idéias por especialidade no CTC, o número de horas/ano de educação continuada e capacitação pactuada com colaboradores na PwC, bem como as mensurações das práticas de compartilhamento no CTC e na Siemens. Tais métricas possuem ressonância de discurso nos valores organizacionais - que incluem termos como aprendizagem, compartilhamento e inovação - e nas práticas de recrutamento, seleção, desenvolvimento e retenção de pessoas.

Outras iniciativas próprias na Siemens do Brasil, utilizadas para acompanhar estrategicamente a evolução da GC, são o Strategic Skill Gap e o KS ENABLED. Conforme dados obtidos mediante pesquisa documental na empresa, O Strategic Skill Gap

"consiste em abrir o mapeamento estratégico dos produtos, das soluções e dos serviços, nas dimensões da tendência de mercado e da relevância para o negócio, em termos de competências estratégicas essenciais para o domínio destes produtos, soluções e serviços. A partir desta abertura, a organização avalia com os colaboradores, de forma a saber se, para estas competências estratégicas, eles são subqualificados, ou supra-qualificados. Os resultados deste mapeamento permitem dirigir estrategicamente 0 investimento em aquisição de conhecimento (ou seja, em formação), e facilitar práticas de job-rotation (socialização de conhecimento).

Já a segunda métrica, conhecida na empresa como KS -Enabled, 
"...representa o quanto a organização partilha adequadamente o seu conhecimento (por unidade de negócio e no geral). Para isso, são medidas duas grandezas, que são a cultura e a prontidão para compartilhar e o uso das práticas e infraestruturas adequadas no momento adequado. Um bom resultado no $\mathrm{KS}$-enabled depende de um bom resultado em ambos os valores (tais métricas são específicas de GC, enquanto o BSC considera outros indicadores)".

Embora possam ser consideradas avançadas quanto ao uso de métricas quantitativas direcionadas para a GC, as organizações estudadas afirmam que não se pode avaliar a gestão do conhecimento somente sob uma perspectiva quantitativa, uma vez que se está gerenciado mudanças culturais, comportamentais e de atitudes.

Por fim, dentre os resultados auferidos pelas organizações em seus programas de GC, destacam-se os seguintes: (a) a redução do ciclo de inovações e a aceleração do tempo de entrega de soluções ao mercado, (b) ampliação da fatia de mercado, aumento do portfolio de negócios e aumento da carteira de clientes, (c) melhoria na colaboração entre as pessoas e equipes e facilidade de se localizar competências, (d) diminuição do re-trabalho e redução de custos, (e) preservação da memória organizacional e aumento da potência de aprendizagem organizacional e (f) antecipação de movimentos estratégicos da concorrência.

\section{Conclusões}

Este artigo relata as motivações, concepções, práticas gerenciais, ênfases, métricas, indicadores e resultados de GC em programas efetivamente implantados em três organizações atuantes no Brasil. Com base nesses elementos, busca-se a proposição de um modelo ou mapa conceitual integrativo. Tal proposta, longe de buscar uma solução definitiva ou um modelo acabado, procura contribuir para a formulação de um melhor entendimento do território da gestão do conhecimento, bem como suas fronteiras e conexões. Elaborou-se, para esse fim, um mapa ou modelo integrativo de GC adaptado daquele originalmente proposto por Choo (1998). A FIG.1, abaixo, apresenta esta proposta de mapeamento conceitual integrativo. 
Gestão do conhecimento ou gestão de organizações da era do conhecimento? Um ensaio teórico-prático a partir de intervenções na realidade brasileira
Rivadávia Correa Drummond de Alvarenga Neto;Ricardo Rodrigues Barbosa; Heitor José Pereira

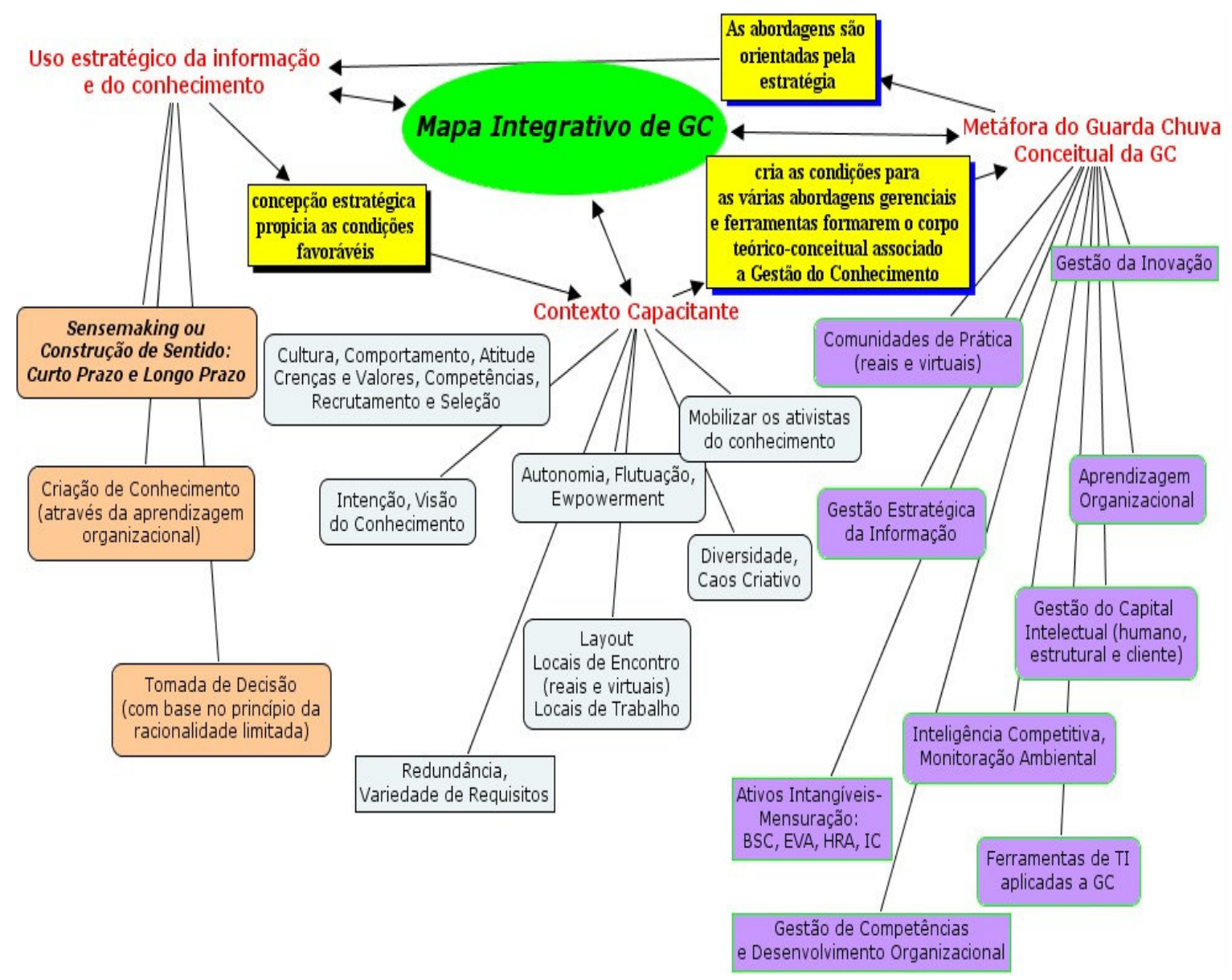

FIGURA 1: Proposta de Mapeamento Conceitual Integrativo da GC

Fonte: ALVARENGA NETO, 2005.

Outro aspecto que se procurou enfatizar no presente trabalho, considerado fundamental para o avanço da pesquisa sobre GC, é o abandono da estéril dissensão derivada de insolucionáveis discussões terminológicas.

As conclusões deste trabalho sugerem que não se gerencia conhecimento, apenas se promove ou se estimula o conhecimento através da criação de contextos organizacionais favoráveis. Assim, a GC assume o significado de uma gestão de e para o conhecimento. Dessa forma, a GC revela-se como um repensar da gestão para as organizações da era do conhecimento. De fato, GC significa gestão na era do conhecimento. Tal afirmativa resulta do entendimento de que a informação e o conhecimento constituem-se como os principais fatores de competitividade dos tempos atuais para organizações e nações. Em outras palavras, as organizações pesquisadas adotantes da GC não gerenciam o conhecimento na acepção estrita e terminológica - apenas se capacitam para o conhecimento - visto que reconhecem que o conhecimento só existe na mente humana e no espaço imaginário entre as fronteiras de mentes criativas em sinergia de propósitos. De fato, o conhecimento pode ser apenas promovido ou estimulado e, assim sendo, o que se gerencia são as condições favoráveis à emergência do novo, que são inovação, criatividade, aprendizagem e 
compartilhamento de informações e conhecimentos relevantes; ou seja, o contexto capacitante.

A GC não se equivale à tecnologia de informação, embora possa ser vista como um conjunto de práticas sustentadas pela TI. É fato que nem todas as iniciativas de GC envolvem tecnologias, como se pode comprovar pelas iniciativas genuinamente brasileiras relatadas neste artigo As conclusões da pesquisa aqui relatada também sugerem que os principais desafios para as organizações comprometidas com a GC são aqueles relativos à cultura organizacional, comportamento humano e criação do contexto capacitante, além da premência da criação de um conjunto de indicadores para se medir os retornos e benefícios de GC.

Ressalta-se também que a GC é altamente política uma vez que, ao se tratar das questões de informação e conhecimento, toca-se diretamente nas questões atinentes ao poder no cerne da organização. É uma mudança de modelo mental, do mote informação é poder para a máxima compartilhar é poder. GC requer gestores do conhecimento e é um processo que não tem fim.

A discussão teórica acerca de uma segunda geração da GC, voltada ao capital humano e à criação do contexto capacitante, já é realidade nas organizações brasileiras estudadas. Tal confirmação revelou-se na seriedade e nos esforços dessas organizações na construção e consolidação de tal contexto. Por fim, não se observou grandes diferenças na GC em empresas de diferentes setores da economia e diferentes atividades-fim. De fato, embora as organizações deste estudo pertençam a diferentes setores da economia brasileira, seus programas de GC são mais semelhantes do que diferentes no que se refere ao seu foco e escopo.

Espera-se que novos estudos sejam realizados para a ampliação da pesquisa e a investigação mais aprofundada de indicadores de desempenho concernentes a avaliação de ativos intangíveis e patrimônios de conhecimento. Portanto, sugere-se que futuros estudos a respeito dos processos de GC nas organizações e de seus respectivos impactos nas pessoas, em especial os efeitos de natureza comportamental.

Se, por um lado, o método de estudo de casos aqui adotado permite investigar em profundidade uma enorme gama de processos organizacionais relacionados com a gestão do conhecimento, não se pode desconhecer a fragilidade dessa abordagem metodológica quanto à generalização de resultados. Portanto, além de se esperar que futuros estudos focalizem outros contextos organizacionais e novas questões relacionadas com o tema aqui explorado, recomenda-se a adoção de estratégias metodológicas que sejam capazes de explorar ângulos complementares da gestão da informação e do conhecimento em contextos organizacionais. 


\section{Referências}

ALVARENGA NETO, R. C. D. Gestão do conhecimento em organizações: proposta de mapeamento conceitual integrativo. 2005. $400 \mathrm{f}$. Tese (Doutorado em Ciência da Informação) - PPGCI, Escola de Ciência da Informação da UFMG, Belo Horizonte.

ARUNACHALAM, S. Information and knowledge in the age of electronic communication: a developing country perspective. Journal of Information Science, vol. 25, n. 6, p. 465-476, 1999

BOURDIEU, P. Introdução a uma sociologia reflexiva. In: simbólico. 2 ed. Rio de Janeiro: Bertrand Brasil, 1998. p. 17-58. O poder

CASTELLS, Manuel. A Sociedade em Rede - Vol.1. São Paulo: Paz e Terra, 2000.

$\mathrm{CHOO}, \mathrm{C} . \mathrm{W}$. Information management for the intelligent organization: the art of scanning the environment. Medford, New Jersey: Information Today, 2002, $3^{\text {rd }}$ edition.

CHOO, C. W. The Knowing Organization: How Organizations Use Information for Construct Meaning, Create Knowledge and Make Decisions. New York : Oxford Press, 1998.

DAVENPORT, E. \& CRONIN, B. Knowledge management: semantic drift or conceptual shift? Journal of Education for Library and Information Science, 41(4): 294-306, 2000.

DAVENPORT, T. H., PRUSAK, L. Conhecimento Empresarial: como as organizações gerenciam o seu capital intelectual. Rio de Janeiro : Campus, 1998.

DRUCKER, Peter F. Post-Capitalist Society. New York, NY: HarperCollins, 1993.

EISENHARDHT, K.M. Building theories from case study research. Academy of Management Review, 1989, vol.14, n.4. 532-550.

GARVIN, D. A. Building a learning organization. Harvard Business Review. Vol. 71 Issue 4, p. 78-91. Jul/Aug 1993.

LASTRES, Helena M. M. \& ALBAGLI, S. Informação e Globalização na Era do Conhecimento. Rio de Janeiro:Campus, 1999.

LYMAN \& VARIAN. How much information 2003? Disponível em (http://www.sims.berkeley.edu/research/projects/how-much-info-2003/ ). Acesso em set. 2004.

MARCH, J. G, SIMON, H. A. Limites cognitivos da racionalidade. In: Teoria das organizações. Rio de Janeiro: Fundação Getúlio Vargas, $1975 . \quad$ p. 192-220 (cap. 6)

MARCHAND, D. A.; DAVENPORT, T. H. Dominando a gestão da informação. Porto Alegre: Bookman, 2004. 
NONAKA, I. \& TAKEUCHI, H. Criação de Conhecimento na Empresa: como as empresas japonesas geram a dinâmica da inovação. Rio de Janeiro: Campus, 1997.

PEREIRA, H. J. Bases conceituais de um modelo de gestão para organizações baseadas no conhecimento. XXII Simpósio de Gestão da Inovação Tecnológica - FIA/USP - Salvador, novembro, 2002 - Anais.

SENGE, P. M. A quinta disciplina: arte, teoria e prática da organização da aprendizagem. São Paulo: Best Seller, 1990.

STEWART, T. A. Capital intelectual. Rio de Janeiro: Campus,1998.

STEWART, Thomas A. A Riqueza do Conhecimento: O Capital Intelectual e a Organização do Século XXI. Rio de Janeiro: Campus, 2002.

SVEIBY, K. E. A Nova Riqueza das Organizações: Gerenciando e Avaliando Patrimônios do Conhecimento. Rio de Janeiro: Campus, 1998.

VON KROGH, G., ICHIJO, K., NONAKA, I. In: Facilitando a criação de conhecimento. Rio de Janeiro: Campus, 2001.

WEICK, K. E. Sensemaking in organizations. Thousand Oaks: Sage Publications, 1995.

WILSON, T. D. The nonsense of 'knowledge management'. Information Research, v.8, n.1, October 2002.

YIN, Robert K. Estudo de caso: planejamento e métodos. Porto Alegre: Bookman, 2001. 